\title{
The first outbreak of methicillin-resistant Staphylococcus aureus in dairy cattle in Poland with evidence of on-farm and intrahousehold transmission
}

\author{
Henryk Krukowski, ${ }^{1 *}$ Zofia Bakuła, ${ }^{2 *}$ Mateusz Iskra, ${ }^{2}$ Alina Olender, ${ }^{3}$ Hanna Bis-Wencel, ${ }^{1}$ \\ and Tomasz Jagielski ${ }^{2}$ (i) \\ ${ }^{1}$ Department of Animal and Environmental Hygiene, University of Life Sciences in Lublin, Akademicka 13, 20-950 Lublin, Poland \\ ${ }^{2}$ Department of Medical Microbiology, Institute of Microbiology, Faculty of Biology, University of Warsaw, I. Miecznikowa 1, 02-096 Warsaw, Poland \\ ${ }^{3}$ Department of Medical Microbiology, Medical University of Lublin, W. Chodźki 1, 20-093 Lublin, Poland
}

\begin{abstract}
Staphylococcus aureus is a widely recognized pathogen responsible for many serious diseases in both humans and animals. It is also one of the major causative agents of bovine mastitis. Methicillin-resistant $S$. aureus (MRSA), although relatively rare in this pathology, has been increasingly reported in livestock animals, mainly in pigs, but also cattle, sheep, and poultry. The recent emergence of livestock-associated (LA-)MRSA is cause for an immediate public health concern due to the risk of zoonotic transmission to humans, and is of particular concern for people who work in animal husbandry or have prolonged contact with livestock animals. This study reports on the first LA-MRSA outbreak in dairy cattle and the first probable case of MRSA transmission between humans and cows in Poland. A single dairy farm located in Eastern Poland was monitored on a regular basis for the occurrence of mastitis. Over a 1-yr study period, 717 quarter-milk samples from 583 cows were collected and examined microbiologically. A total of 5 MRSA isolates from as many cows with subclinical mastitis were cultured. They all belonged to the same outbreak, given a 2-mo time window in which they were identified. During the outbreak, 24 oral and nasal swabs were voluntarily taken from 6 people: a milker, a veterinarian, and 4 members of the veterinarian's family. Eight swabs from a milker, veterinarian, and 2 family members yielded positive MRSA cultures. All MRSA isolates were genotyped with a combination of multiple-locus variable number tandem repeat analysis, multilocus sequence typing, and staphylococcal protein A gene (spa) typing. Eleven bovine $(\mathrm{n}=5$; 5 cases) and human ( $\mathrm{n}=6 ; 4$ cases $)$ isolates showed an
\end{abstract}

Received January 30, 2020.

Accepted June 12, 2020.

*These authors contributed equally to this work.

$\dagger$ Corresponding author: t.jagielski@biol.uw.edu.pl identical drug-susceptibility profile and were indistinguishable upon multiple-locus variable number tandem repeat analysis (pattern A), multilocus sequence typing (ST398) and spa (t034) typing. The results of this study provide the evidence of transmission of MRSA between humans and cows, and between humans in the family setting. This work, despite being a preliminary investigation, underscores the risk of intra- and interspecies transmission of LA-MRSA and urges enhancement of the existing biosecurity measures aimed at preventing MRSA (and other milk pathogens) spread at both the farm- and household levels.

Key words: bovine mastitis, outbreak, transmission, methicillin-resistant Staphylococcus aureus, humans

\section{INTRODUCTION}

Staphylococcus aureus is one of the major human pathogens that cause a wide variety of clinical manifestations ranging from localized, superficial skin lesions to severe, life-threatening invasive diseases (Turner et al., 2019). The emergence of methicillin-resistant S. aureus (MRSA) strains since the early 1960s has gravely compounded the management of $S$. aureus infections, posing a significant therapeutic challenge (Boswihi and Udo, 2018; Turner et al., 2019).

Before the mid-1990s, MRSA strains were mostly associated with hospitals and other healthcare facilities. However, in the early 2000s, MRSA infections escalated among patients without prior exposure to healthcare environments. These cases, referred to as communityacquired, are caused by strains that are genetically distinct from nosocomial MRSA and, unlike nosocomial strains, they exhibit enhanced virulence and fitness, which contribute to their rapid dissemination in the community (Udo, 2013; Boswihi and Udo, 2018). Finally, there is a growing evidence that livestock constitutes an important reservoir of MRSA strains with the potential of zoonotic transmission (Pantosti, 2012). These livestock-associated (LA-)MRSA strains 
have been isolated from pigs, cattle, horses, and poultry (Nemati et al., 2008; van Duijkeren et al., 2010; Tavakol et al., 2012; Locatelli et al., 2017). Intra- and interspecies transmission of LA-MRSA, including zoonotic transmission of LA-MRSA strains from livestock to humans, has been amply described in the literature, with people living and working in close proximity to farm animals consistently identified as being at higher risk of MRSA acquisition (Cuny et al., 2009; van Duijkeren et al., 2010; van Duijkeren et al., 2016; Schnitt and Tenhagen, 2019).

In this study, we describe the first LA-MRSA outbreak in dairy cattle in Poland and document the first putative case of direct transmission of MRSA between cows and humans in our country.

\section{MATERIALS AND METHODS}

\section{Study Sample}

The study was conducted on a dairy farm (herd size: 806 cows) located in Lublin Province, Eastern Poland, over a 1-yr period (from January to December 2018). Clinical examination of the animals and milk-quality assessment were carried out as described previously (Jagielski et al., 2019a). A total of 717 quarter-milk samples (positive on California mastitis test) were collected from 583 cows with clinical (28) and subclinical (555) mastitis, following aseptic procedures as described by the National Mastitis Council (2017).

Twenty-four oral and nasal swabs were collected voluntarily from 6 people: a milker, a veterinarian, and 4 members of the veterinarian's family (his wife, 2 sons, and daughter). The swabs were taken from both nostrils and the throat (3 sites) from each person. All swabbings were performed once, except for the veterinarian and the milker, who were sampled twice. The samples were taken upon specific request of the veterinarian. All samples were transported under refrigeration $\left(4^{\circ} \mathrm{C}\right)$ to the laboratory for microbiological evaluation.

\section{Ethical Considerations}

Informed consent was obtained from all human subjects and confidentiality was ensured by anonymization of the data. Thus, ethical approval was not required with local legislation.

\section{Primary Isolation, Culture, and Species Identification}

Quarter-milk samples $(10 \mu \mathrm{L})$ were inoculated onto Columbia agar with $5 \%$ sheep blood (Oxoid, Basingstoke, UK). Cultures were incubated aerobically at $37^{\circ} \mathrm{C}$ for up to $96 \mathrm{~h}$.
Human oral and nasal swabs were first transferred into the brain heart infusion broth with $2 \% \mathrm{NaCl}(\mathrm{Ox}-$ oid) and, after overnight incubation at $37^{\circ} \mathrm{C}, 100-\mu \mathrm{L}$ culture samples were plated onto mannitol-salt-agar (Oxoid) supplemented with $75 \mathrm{mg} / \mathrm{L}$ aztreonam and 6 $\mathrm{mg} / \mathrm{L}$ oxacilline (Sigma-Aldrich, St. Louis, MO). Cultures were incubated aerobically at $37^{\circ} \mathrm{C}$ for up to $96 \mathrm{~h}$.

Colonies suspected to be $S$. aureus were subjected to species identification, which included Gram staining, oxidase, catalase, and coagulase-activity testing, performed according to standard laboratory procedures (Lancette and Tatini, 1992).

\section{Drug-Susceptibility Testing}

Antimicrobial susceptibility was performed on Mueller-Hinton agar (Oxoid) using the disk diffusion method according to EUCAST recommendations and clinical zone diameter breakpoints provided therein (EUCAST, 2018). Briefly, 24-h cultures of S. aureus isolates were used to prepare suspensions in sterile $0.85 \% \mathrm{NaCl}$ equivalent to $0.5 \mathrm{McFarland}$ turbidity standard. The suspensions were subsequently used to inoculate the Mueller-Hinton agar plates. Disks impregnated with antimicrobial agents (Oxoid) were placed on the surface of each of the inoculated agar medium. Incubation was conducted aerobically at $35 \pm 1^{\circ} \mathrm{C}$ for $18 \pm 2$ h. After incubation, the development of the zones of inhibition of bacterial growth around the disks was observed and their diameters measured $(\mathrm{mm})$. The S. aureus reference strain ATCC 29213 was used as the control.

The cefoxitin $(30 \mu \mathrm{g})$ disk diffusion method was used to detect methicillin resistance. An inhibition zone diameter of $<21 \mathrm{~mm}$ was indicative of a methicillinresistant phenotype.

All MRSA isolates were further subjected to supplementary antimicrobial susceptibility testing by disk diffusion method, with amikacin $(30 \mu \mathrm{g}$; sensitive (SV) $\geq 18$; resistant $(\mathbf{R})<16)$, chloramphenicol $(30 \mu \mathrm{g} ; \mathrm{SV}$ $\geq 18 ; \mathrm{R}<18$ ), ciprofloxacin (5 $\mu \mathrm{g} ; \mathrm{SV} \geq 21 ; \mathrm{R}<21$ ), clindamycin $(2 \mu \mathrm{g} ; \mathrm{SV} \geq 22 ; \mathrm{R}<19)$, co-trimoxazole $(23.75 / 1.25 \mu \mathrm{g} ; \mathrm{SV} \geq 17 ; \mathrm{R}<14)$, fusidic acid $(10 \mu \mathrm{g}$; $\mathrm{SV} \geq 24 ; \mathrm{R}<24)$, gentamicin $(10 \mu \mathrm{g} ; \mathrm{SV} \geq 18 ; \mathrm{R}<$ 18), mupirocin $(20 \mu \mathrm{g} ; \mathrm{SV} \geq 30 ; \mathrm{R}<18)$, norfloxacin $(10 \mu \mathrm{g} ; \mathrm{SV} \geq 17)$, and tetracycline $(30 \mu \mathrm{g} ; \mathrm{SV} \geq 22$; $\mathrm{R}<19)$.

\section{DNA Extraction}

Genomic DNA was extracted from $S$. aureus cultures grown on brain heart infusion agar with a GeneMATRIX Environmental DNA and RNA purification kit (EURx, Gdańsk, Poland) according to the manufacturer's pro- 
tocol. The DNA concentration was quantified with the NanoDropOne spectrophotometer (Thermo Scientific, Waltham, MA) and stored at $-20^{\circ} \mathrm{C}$ until used.

\section{Genotyping}

All strains were genotyped with 3 molecular methods: multiple-locus variable number tandem repeat analysis (MLVA; Sabat et al., 2003), multilocus sequence typing (MLST; Enright et al., 2000), and staphylococcal protein A gene (spa) typing (Harmsen et al., 2003).

MLVA Typing. A set of PCR primers to simultaneously amplify the hypervariable regions of the $s p a$, $s s p A, \operatorname{clf} A, \operatorname{clf} B, \operatorname{sdr} C, \operatorname{sdr} D$, and $s d r E$ genes was used, as described by Sabat et al. (2003). The DNA fragments were separated electrophoretically in $2 \%$ agarose gels and visualized by staining with ethidium bromide $(0.5 \mu \mathrm{g} / \mathrm{mL})$ and exposure to UV light $(\lambda=320 \mathrm{~nm})$ with BioDoc-It UVP Transilluminator (Analytik Jena, Jena, Germany).

MLST Typing. Seven housekeeping genes (i.e., arc, aroE, glp, gmk, pta, tpi, and yqiL) were interrogated in the MLST scheme and their respective fragments were amplified by using primers and conditions described elsewhere (Enright et al., 2000). Amplicons were purified with the Clean-Up kit (A\&A Biotechnology, Gdynia, Poland) and sequenced in both directions at the Genomed DNA sequencing laboratory (Warsaw, Poland). Sequence data were assembled and analyzed with the Clone Manager version 8 software (Sci-Ed Software, https://www.scied.com), and the resulting consensus sequences were aligned against the $S$. aureus MLST database (http://saureus.beta.mlst.net/).

Spa Typing. The variable repeat region X of the protein A-encoding spa gene was amplified by PCR with primers and conditions provided elsewhere (Ridom Bioinformatics, https://www.ridom.de/). Sequence data were assembled and analyzed with Clone Manager, and the resulting consensus sequences were aligned against the spaTyper 1.0 database (Bartels et al., 2014).

\section{RESULTS}

During the 12-mo study period, $12 \mathrm{~S}$. aureus isolates were recovered from milk samples (out of 717 tested; $1.7 \%$ ) collected from 12 cows (out of 583 tested; $2.1 \%$ ), all with subclinical mastitis. Five (41.7\%) S. aureus isolates were MRSA. The first isolations of methicillinsusceptible and methicillin-resistant $S$. aureus were achieved in April and June, respectively. The last MRSA isolate from milk was cultured in July (Table 1).

Eight body swabs (out of 24 tested; 33.3\%), including 5 nasal and 3 oral samples, yielded growth of $S$. aureus. All of these isolates exhibited MRSA phenotype, as

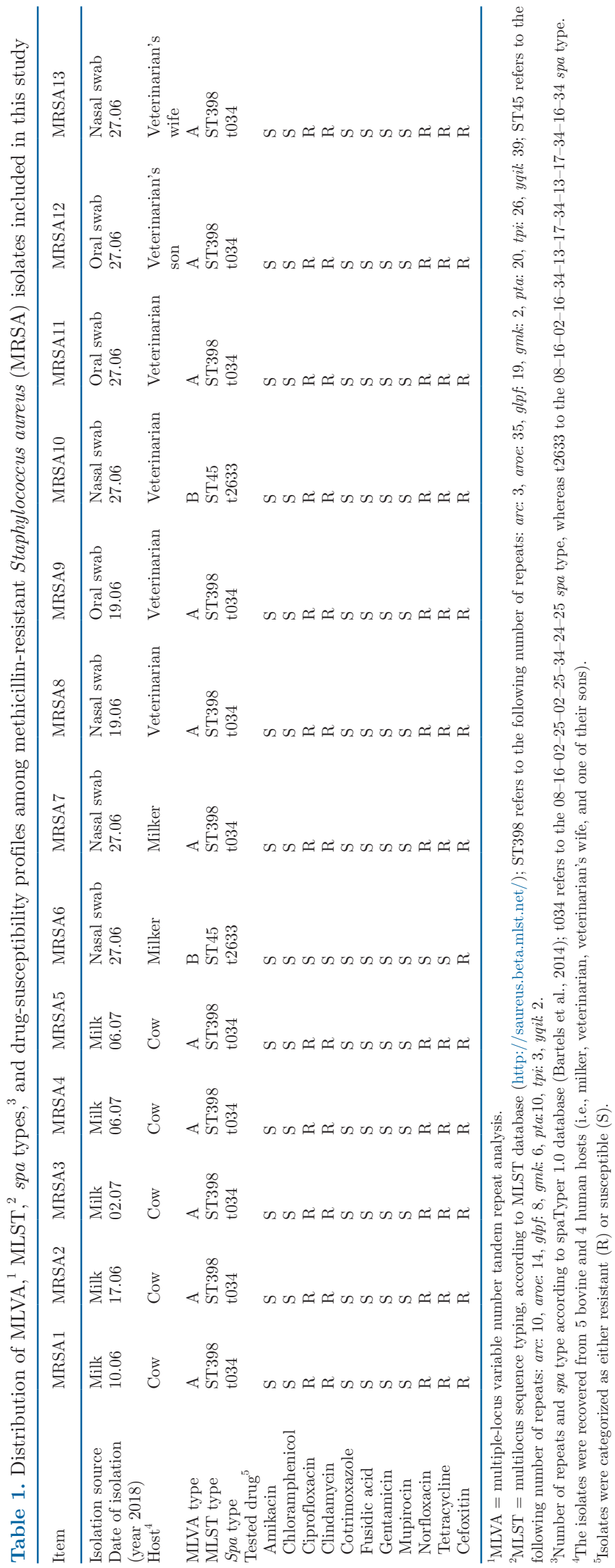


they were resistant to cefoxitin. They were all collected in June and originated from a veterinarian $(\mathrm{n}=4)$, his wife $(\mathrm{n}=1)$, his son $(\mathrm{n}=1)$, and a milker $(\mathrm{n}=2)$.

All milk isolates $(\mathrm{n}=5)$ were fully susceptible to amikacin, chloramphenicol, cotrimoxazole, fusidic acid, gentamicin, and mupirocin, yet showed resistance to ciprofloxacin, clindamycin, norfloxacin, and tetracycline. All human isolates had exactly the same drugsusceptibility profile, except 1 isolate (MRSA6) that was resistant to cefoxitin only (Table 1).

Genotyping was performed on all $(\mathrm{n}=13)$ MRSA isolates (Table 1). Five bovine ( 5 cases) and 6 human (4 cases) isolates were indistinguishable upon MLVA typing (pattern A), and harbored identical MLST (ST398) and spa (t034) types (Figure 1; Table 1). The other 2 human isolates (2 cases) shared identical MLVA (pattern B), MLST type (ST45), and spa type (t2633) (Figure 1; Table 1).

\section{DISCUSSION}

In the etiology of bovine mastitis, $S$. aureus plays a leading role, accounting for 6 to $74 \%$ of infections (Persson et al., 2011; Hoque et al., 2018; Poutrel et al., 2018; Pumipuntu et al., 2019). Since the first description of MRSA in dairy cattle in the 1970s, isolations of MRSA from mastitic cows have been reported from across the world, representing up to $29 \%$ of all $S$. aureus strains cultured (Prashanth et al., 2011). In Poland, the preva- lence of staphylococcal mastitis among dairy herds has been calculated to be 17 to $44 \%$ (Malinowski et al., 2006; Sztachańska et al., 2016; Jagielski et al., 2019b). Until this study, however, no MRSA isolates have been reported from bovine samples in Poland. In contrast, studies performed in Poland's neighbors have shown the prevalence of MRSA in bulk-tank milk samples from dairy herds in Germany, Ukraine, and Czech Republic at levels of $5.7,6.5$, and $38 \%$, respectively (Tenhagen et al., 2014; Berhilevych et al., 2017; Tegegne et al., 2019).

Several molecular typing methods have been used for epidemiological investigations of $S$. aureus infections (Tenover et al., 2009; Jagielski et al., 2014; Locatelli et al., 2017). Currently, MLST typing with 7 housekeeping genes (Enright et al., 2000), and spa typing based on the protein A-coding gene (Bartels et al., 2014) are considered frontline tools in the molecular epidemiology of MRSA worldwide. By using these techniques, it has been demonstrated that many $S$. aureus lineages display strong host specificity and others may colonize or infect a variety of animal species (Pantosti, 2012; Aires-de-Sousa, 2017). Furthermore, different lineages show a considerable variation in their geographical distributions (Monistero et al., 2018).

Although several studies have addressed the issue of transmission of MRSA among humans and animals (van Duijkeren et al., 2004; Angen et al., 2017; Zhou et al., 2018; Pirolo et al., 2019), few have demonstrated, directly or indirectly, that such transmission occurs

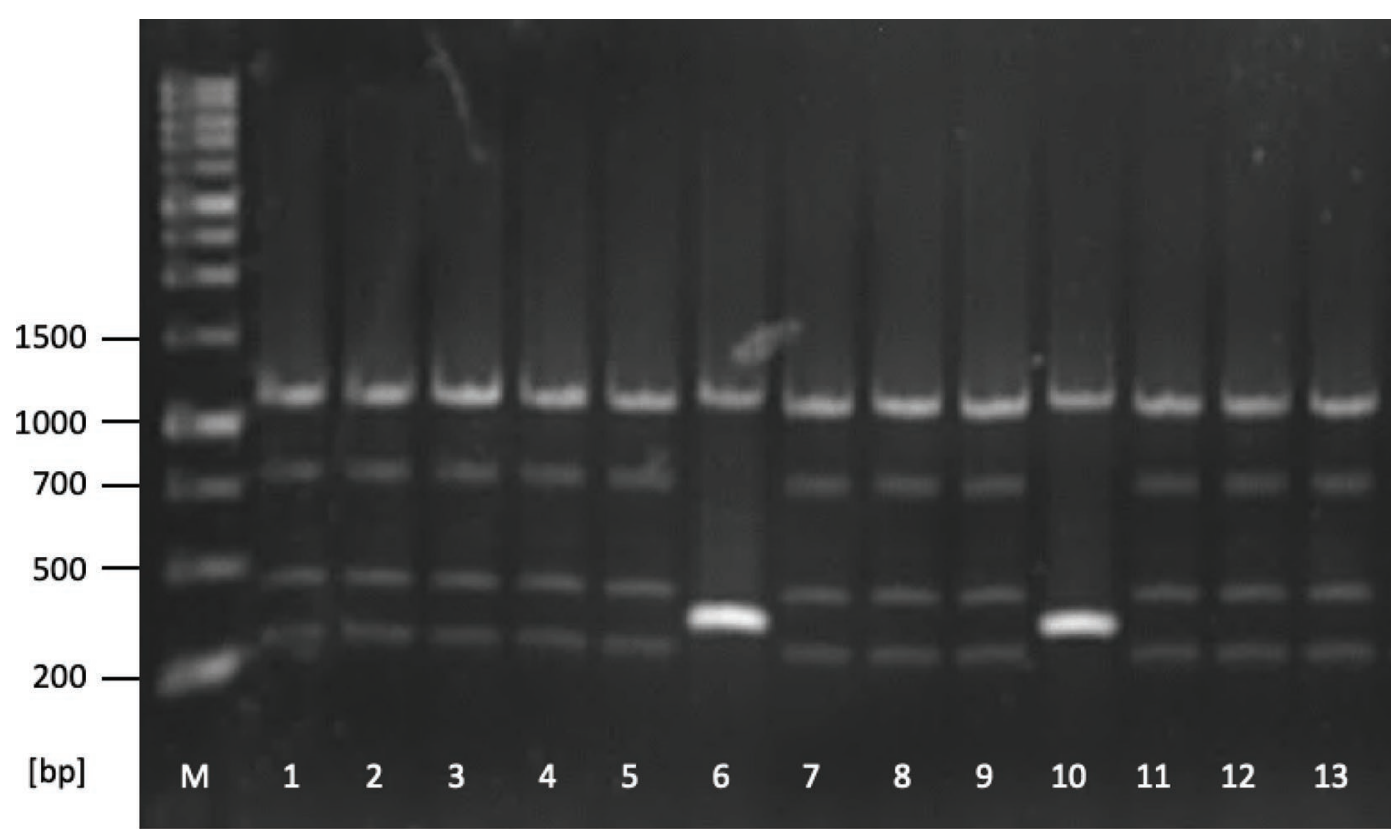

Figure 1. Multiple-locus variable number tandem repeat analysis patterns of methicillin-resistant Staphylococcus aureus (MRSA) isolates under the study. Lane designations (1-13) correspond to isolate numbers (MRSA 1-13; see Table 1); M = size marker (Gene Ruler 1 kB, Thermo Fisher Scientific, Waltham, MA). 
among humans and dairy cows (Juhász-Kaszanyitzky et al., 2007; Sakwinska et al., 2011; Locatelli et al., 2017; Sato et al., 2017; Schmidt et al., 2017).

In this study, a triple-modality typing approach showed that all bovine MRSA isolates, and all but 2 human MRSA isolates, were identical, representing the MSLT sequence type (ST)398 and spa type t034 genotype.

The ST398 represents the most prevalent LA-MRSA lineage in Europe and North America, and is quite common in Asia. It was first identified among pigs (Armand-Lefevre et al., 2005), but subsequent studies have reported its recovery from other animal species including dogs, horses, poultry, and dairy cattle (Nemati et al., 2008; Nienhoff et al., 2009; Fessler et al., 2010; Vanderhaeghen et al., 2010; van Duijkeren et al., 2010; Sakwinska et al., 2011; Tavakol et al., 2012; Sharma et al., 2016; Kadlec et al., 2019). With the escalating dissemination of the ST398 among food-producing and companion animals, there has been an increased prevalence of human colonization with that genotype, especially among people occupationally exposed to animals and their products (e.g., farmers, veterinarians, abattoir workers). The MRSA ST398 was shown to colonize up to $86 \%$ of pig farmers, $37 \%$ of cattle- or poultryfarmers, and $45 \%$ of pig-care veterinarians (Goerge et al., 2017). Furthermore, several studies have pointed to the accumulation of MRSA ST398 in households of colonized livestock workers, suggesting human-tohuman transmission (Cuny et al., 2009; Verkade et al., 2014; Bosch et al., 2015). Finally, although generally associated with colonization, MRSA ST398 has been implicated in human infections of variable clinical spectrum and relevance, including fatal events (Becker et al., 2017).

In Poland, MRSA strains of ST398 were first isolated in 2008 on pig farms during the first MRSA baseline survey on dust samples from pig holdings in the European Union (EFSA, 2009). Subsequently, the ST398 MRSA strains were recovered from nasal swabs from pig veterinarians (Marszałek et al., 2009). More recently, ST398 has been described as a predominant MRSA clade on Polish swine farms (Mroczkowska et al., 2017). However, never before has this genotype been cultured from bovine milk in Poland. Noteworthy, the finding of MRSA ST398 in dairy milk cows was described in 2 countries neighboring Poland, namely Germany (Fessler et al., 2010; Kadlec et al., 2019) and Czech Republic (Tegegne et al., 2019). In this study, all MRSA-infected cows presented with subclinical mastitis. The overall number of MRSA-positive cows was $0.9 \%(5 / 583)$, which was similar to that in Germany $(0.3 \%)$, but drastically lower compared with what was observed in a single herd in Italy (60\%; Locatelli et al.,
2017; Kadlec et al., 2019). Interestingly, the proportion of MRSA among $S$. aureus isolates cultured from our herd $(41.7 \%)$ was much higher than in other studies (1.2-9.3\%) (Juhász-Kaszanyitzky et al., 2007; Vanderhaeghen et al., 2010; Sakwinska et al., 2011; Luini et al., 2015; Kadlec et al., 2019), except the Italian work, where almost all $S$. aureus isolates tested were methicillin-resistant (Locatelli et al., 2017). As in this study, cases of MRSA mastitis from other European countries were either exclusively or predominantly caused by ST398 (Vanderhaeghen et al., 2010; Sakwinska et al., 2011; Tavakol et al., 2012; Luini et al., 2015; Kadlec et al., 2019). All ST398 isolates in our study were also identified as belonging to the spa type t034, which has regularly been associated with the ST398 lineage and, together with spa type t011, represent the most common MRSA spa types circulating in both bovine and porcine populations (Fessler et al., 2010; Sharma et al., 2016; Tegegne et al., 2019).

Despite its multihost specificity and clearly evidenced potential for interspecies transmission (including zoonotic route), the ST398 lineage contributes only marginally $(<2 \%)$ to the overall MRSA burden in human population. However, marked differences exist between countries, depending on the intensiveness of the dairy agriculture and efficacy of infection surveillance and control programs for MRSA in the healthcare sector (Aires-de-Sousa, 2017).

Still, human-to-human transmission of MRSA ST398 occurred much less frequently than transmission of MRSA non-ST398 strains (Verkade et al., 2014). In this study, out of 6 human MRSA isolates sharing an identical phenotype (drug-susceptibility profile) and genotype determined by 3 typing methods with bovine MRSA isolates, 1 was from a milker, 3 from a veterinarian, 1 from the veterinarian's wife, and 1 from their son. This suggests transmission of 2 types: on-farm transmission between dairy cattle and livestock professionals and within-household transmission between the veterinarian and his family. The primary source of infection in the herd remains unknown. Consequently, it is unclear whether on-farm transmission was from the bovine-to-human or human-to-bovine route. Given that the clonal complex 398 is particularly associated with pig farming, with its spa t034 variant being a typical pig-borne genotype, it is possible that the MRSA strain was introduced into the dairy herd by the veterinarian, as he payed regular visits to pig facilities. The pathogen might then have spread within the herd either through a direct contact between the animals or during the milking process via the contaminated milker's hands, udder clothes, or teat cup liners. In the few studies which explored transmission of LA-MRSA strains between farm personnel and dairy cattle, the direction 
of transmission could not be unequivocally established (Juhász-Kaszanyitzky et al., 2007; Fessler et al., 2010; Sakwinska et al., 2011; Locatelli et al., 2017; Sato et al., 2017; Schmidt et al., 2017). Seldom was it conjecturally inferred from comparison of specific genotype frequencies in human and bovine populations. Thus, finding a bovine isolate carrying a typically human genotype served as a proxy for human-to-bovine transmission, and vice versa (Sakwinska et al., 2011).

In accordance with previous studies, our present study demonstrated the potential of LA-MRSA to be transmitted between humans (Cuny et al., 2009; Bosch et al., 2015). Here, transmission between a veterinarian and his 2 family members was supported by the fact that those 2 had no direct contact with livestock animals or their environment.

Last, it is worth commenting briefly on culturing 2 different MRSA genotypes from the same anatomical site of 2 individuals. The nasal swabs from the veterinarian and the milker, which yielded 2 strains each (1 of ST398 and 1 of ST45) were concerning because ST45 represents one of the predominant, essentially hospital-acquired, human clones in Europe and beyond (Stefani et al., 2012). The clonal complex CC45-related genotypes are common in both asymptomatic carriage isolates and invasive isolates involved in severe nosocomial infections (Moore et al., 2010). The occurrence of the ST45 MRSA in a veterinarian and a milker may be because they have known each other and have worked together for many years during routine veterinary inspections of the herds.

The co-existence of multiple $S$. aureus genotypes (strains) in human nasal carriers has already been reported, albeit the clinical significance of such co-colonization remains obscure. Speculatively, it may influence the pathogenicity and virulence of individual strains, not excluding their transmission capacities (Votintseva et al., 2014).

\section{CONCLUSIONS}

This study documents, for the first time in Poland, an outbreak of subclinical mastitis in dairy cows due to MRSA. The strain involved in the outbreak belonged to the major LA-MRSA clonal lineage CC398. Our results also provide the evidence of transmission of that strain between humans and cows, and between humans in the family setting. This work was only preliminary, and further investigations need to be developed to better recognize the prevalence of MRSA among dairy cattle and the extent of MRSA carriage among farm professionals and their household members in Poland. Nevertheless, our findings underscore the risk of intra- and interspecies transmission of LA-MRSA and urge enhancement of the existing biosecurity measures aimed at preventing MRSA (and other milk pathogens) spread at both farm- and household levels.

\section{ACKNOWLEDGMENTS}

The authors have not stated any conflicts of interest.

\section{REFERENCES}

Aires-de-Sousa, M. 2017. Methicillin-resistant Staphylococcus aureus among animals: Current overview. Clin. Microbiol. Infect. 23:373380. https://doi.org/10.1016/j.cmi.2016.11.002.

Angen, Ø., L. Feld, J. Larsen, K. Rostgaard, R. Skov, A. M. Madsen, and A. R. Larsen. 2017. Transmission of methicillin-resistant Staphylococcus aureus to human volunteers visiting a swine farm. Appl. Environ. Microbiol. 83:e01489-e17. https://doi.org/10 .1128/AEM.01489-17.

Armand-Lefevre, L., R. Ruimy, and A. Andremont. 2005. Clonal comparison of Staphylococcus aureus isolates from healthy pig farmers, human controls, and pigs. Emerg. Infect. Dis. 11:711-714. https:/ /doi.org/10.3201/eid1105.040866.

Bartels, M. D., A. Petersen, P. Worning, J. B. Nielsen, H. LarnerSvensson, H. K. Johansen, L. P. Andersen, J. O. Jarløv, K. Boye, A. R. Larsen, and H. Westh. 2014. Comparing whole-genome sequencing with Sanger sequencing for spa typing of methicillinresistant Staphylococcus aureus. J. Clin. Microbiol. 52:4305-4308. https://doi.org/10.1128/JCM.01979-14.

Becker, K., B. Ballhausen, B. C. Kahl, and R. Köck. 2017. The clinical impact of livestock-associated methicillin-resistant Staphylococcus aureus of the clonal complex 398 for humans. Vet. Microbiol. 200:33-38. https://doi.org/10.1016/j.vetmic.2015.11.013.

Berhilevych, O. M., V. V. Kasianchuk, M. D. Kukhtyn, I. M. Lotskin, T. O. Garkavenko, and P. A. Shubin. 2017. Characteristics of antibiotic sensitivity of Staphylococcus aureus isolated from dairy farms in Ukraine. Regul. Mech. Biosyst. 8:559-563. https://doi .org/10.15421/021786.

Bosch, T., E. Verkade, M. van Luit, F. Landman, J. Kluytmans, and L. M. Schouls. 2015. Transmission and persistence of livestock-associated methicillin-resistant Staphylococcus aureus among veterinarians and their household members. Appl. Environ. Microbiol. 81:124-129. https://doi.org/10.1128/AEM.02803-14.

Boswihi, S. S., and E. E. Udo. 2018. Methicillin-resistant Staphylococcus aureus: An update on the epidemiology, treatment options and infection control. Curr. Med. Res. Pract. 8:18-24. https://doi.org/ 10.1016/j.cmrp.2018.01.001

Cuny, C., R. Nathaus, F. Layer, B. Strommenger, D. Altmann, and W. Witte. 2009. Nasal colonization of humans with methicillinresistant Staphylococcus aureus (MRSA) CC398 with and without exposure to pigs. PLoS One 4:e6800. https://doi.org/10.1371/ journal.pone.0006800.

EFSA. 2009. Analysis of the base-line survey on the prevalence of methicillin-resistant Staphylococcus aureus (MRSA) in holdings with breeding pigs, in the EU, 2008. Part A: MRSA prevalence estimates. EFSA J. 7:1376. https://doi.org/10.2903/j.efsa.2009 .1376.

Enright, M. C., N. P. J. Day, C. E. Davies, S. J. Peacock, and B. G. Spratt. 2000. Multilocus sequence typing for characterization of methicillin-resistant and methicillin-susceptible clones of Staphylococcus aureus. J. Clin. Microbiol. 38:1008-1015. https://doi.org/10 .1128/JCM.38.3.1008-1015.2000.

EUCAST. 2018. The European Committee on Antimicrobial Susceptibility Testing. Breakpoint tables for interpretation of MICs and zone diameters. Version 8.1, 2018. Accessed Jul. 2020. http://www .eucast.org/clinical_breakpoints/.

Fessler, A., C. Scott, K. Kadlec, R. Ehricht, S. Monecke, and S. Schwarz. 2010. Characterization of methicillin-resistant Staphylo- 
coccus aureus ST398 from cases of bovine mastitis. J. Antimicrob. Chemother. 65:619-625. https://doi.org/10.1093/jac/dkq021.

Goerge, T., M. B. Lorenz, S. van Alen, N. O. Hubner, K. Becker, and R. Kock. 2017. MRSA colonization and infection among persons with occupational livestock exposure in Europe: Prevalence, preventive options and evidence. Vet. Microbiol. 200:6-12. https://doi .org/10.1016/j.vetmic.2015.10.027.

Harmsen, D., H. Claus, W. Witte, J. Rothganger, H. Claus, D. Turnwald, and U. Vogel. 2003. Typing of methicillin-resistant Staphylococcus aureus in a university hospital setting by using novel software for spa repeat determination and database management. J. Clin. Microbiol. 41:5442-5448. https://doi.org/10.1128/JCM.41 .12.5442-5448.2003.

Hoque, M. N., Z. C. Das, A. N. M. A. Rahman, M. G. Haider, and M. A. Islam. 2018. Molecular characterization of Staphylococcus aureus strains in bovine mastitis milk in Bangladesh. Int. J. Vet. Sci. Med. 6:53-60. https://doi.org/10.1016/j.ijvsm.2018.03.008.

Jagielski, T., H. Krukowski, M. Bochniarz, T. Piech, K. Roeske, Z. Bakuła, Ł. Wlazło, and P. Woch. 2019b. Prevalence of Prototheca spp. on dairy farms in Poland - A cross-country study. Microb. Biotechnol. 12:556-566. https://doi.org/10.1111/1751-7915.13394.

Jagielski, T., E. Puacz, A. Lisowski, P. Siedlecki, W. Dudziak, J. Międzobrodzki, and H. Krukowski. 2014. Short communication: Antimicrobial susceptibility profiling and genotyping of Staphylococcus aureus isolates from bovine mastitis in Poland. J. Dairy Sci. 97:6122-6128. https://doi.org/10.3168/jds.2014-8321.

Jagielski, T., K. Roeske, Z. Bakula, T. Piech, Ł. Wlazło, M. Bochniarz, P. Woch, and H. Krukowski. 2019a. A survey on the incidence of Prototheca mastitis in dairy herds in Lublin province, Poland. J. Dairy Sci. 102:619-628. https://doi.org/10.3168/jds.2018-15495.

Juhász-Kaszanyitzky, E., S. Jánosi, P. Somogyi, A. Dán, L. van der Graaf-van Bloois, E. van Duijkeren, and J. A. Wagenaar. 2007. MRSA transmission between cows and humans. Emerg. Infect. Dis. 13:630-632. https://doi.org/10.3201/eid1304.060833.

Kadlec, K., M. Entorf, and T. Peters. 2019. Occurrence and characteristics of livestock-associated methicillin-resistant Staphylococcus aureus in quarter milk samples from dairy cows in Germany. Front. Microbiol. 10:1295. https://doi.org/10.3389/fmicb.2019.01295.

Lancette, G. A., and S. R. Tatini. 1992. Staphylococcus aureus. Pages 533-550 in Compendium of Methods for the Microbiological Examination of Foods, third ed. C. Vanderzant and D.F. Splittstoesser, ed. American Public Health Association, Washington, DC.

Locatelli, C., P. Cremonesi, A. Caprioli, V. Carfora, A. Ianzano, A. Barberio, S. Morandi, A. Casula, B. Castiglioni, V. Bronzo, and P. Moroni. 2017. Occurrence of methicillin-resistant Staphylococcus aureus in dairy cattle herds, related swine farms, and humans in contact with herds. J. Dairy Sci. 100:608-619. https://doi.org/10 $.3168 /$ jds.2016-11797.

Luini, M., P. Cremonesi, G. Magro, V. Bianchini, G. Minozzi, B. Castiglioni, and R. Piccinini. 2015. Methicillin-resistant Staphylococcus aureus (MRSA) is associated with low within-herd prevalence of intra-mammary infections in dairy cows: Genotyping of isolates. Vet. Microbiol. 178:270-274. https://doi.org/10.1016/j.vetmic 2015.05.010.

Malinowski, E., H. Lassa, A. Kłossowska, S. Smulski, H. Markiewicz, and M. Kaczmarowski. 2006. Etiological agents of dairy cows' mastitis in western part of Poland. Pol. J. Vet. Sci. 9:191-194.

Marszałek, N., J. Empel, J. Żmudzki, A. Nowak, Z. Pejsak, and W. Hryniewicz. 2009. First methicillin resistant Staphylococcus aureus (MRSA) of ST398 isolated in Poland from nasal carriers. 19th European Congress of Clinical Microbiology and Infectious Diseases, May 16-19, 2009, Helsinki, Finland.

Monistero, V., H. U. Graber, C. Pollera, P. Cremonesi, B. Castiglioni, E. Bottini, A. Ceballos-Marquez, L. Lasso-Rojas, V. Kroemker, N. Wente, I. M. Petzer, C. Santisteban, J. Runyan, M. Veiga Dos Santos, B. G. Alves, R. Piccinini, V. Bronzo, M. S. Abbassi, M. B. Said, and P. Moroni. 2018. Staphylococcus aureus isolates from bovine mastitis in eight countries: Genotypes, detection of genes encoding different toxins and other virulence genes. Toxins (Basel) 10:247. https://doi.org/10.3390/toxins10060247.
Moore, C. L., P. Osaki-Kiyan, M. Perri, S. Donabedian, N. Z. Haque, A. Chen, and M. J. Zervos. 2010. USA600 (ST45) methicillin-resistant Staphylococcus aureus bloodstream infections in urban Detroit. J. Clin. Microbiol. 48:2307-2310. https://doi.org/10.1128/ JCM.00409-10.

Mroczkowska, A., J. Żmudzki, N. Marszałek, M. Orczykowska-Kotyna, I. Komorowska, A. Nowak, A. Grzesiak, E. Czyżewska-Dors, A. Dors, Z. Pejsak, W. Hryniewicz, T. Wyszomirski, and J. Empel. 2017. Livestock-associated Staphylococcus aureus on Polish pig farms. PLoS One 12:e0170745. https://doi.org/10.1371/journal .pone. 0170745 .

National Mastitis Council. 2017. Laboratory Handbook of Bovine Mastitis. NMC Inc., Madison, WI.

Nemati, M., K. Hermans, U. Lipinska, O. Denis, A. Deplano, M. Struelens, L. A. Devriese, F. Pasmans, and F. Haesebrouck. 2008. Antimicrobial resistance of old and recent Staphylococcus aureus isolates from poultry: First detection of livestock-associated methicillin-resistant strain ST398. Antimicrob. Agents Chemother. 52:3817-3819. https://doi.org/10.1128/AAC.00613-08.

Nienhoff, U., K. Kadlec, I. F. Chaberny, J. Verspohl, G. F. Gerlach, S. Schwarz, D. Simon, and I. Nolte. 2009. Transmission of methicillin-resistant Staphylococcus aureus strains between humans and dogs: two case reports. J. Antimicrob. Chemother. 64:660-662. https://doi.org/10.1093/jac/dkp243.

Pantosti, A. 2012. Methicillin-resistant Staphylococcus aureus associated with animals and its relevance to human health. Front. Microbiol. 3:127. https://doi.org/10.3389/fmicb.2012.00127.

Persson, Y., A. K. J. Nyman, and U. Grönlund-Andersson. 2011. Etiology and antimicrobial susceptibility of udder pathogens from cases of subclinical mastitis in dairy cows in Sweden. Acta Vet. Scand. 53:36. https://doi.org/10.1186/1751-0147-53-36.

Pirolo, M., D. Visaggio, A. Gioffrè, I. Artuso, M. Gherardi, G. Pavia, P. Samele, L. Ciambrone, R. Di Natale, G. Spatari, F. Casalinuovo, and P. Visca. 2019. Unidirectional animal-to-human transmission of methicillin-resistant Staphylococcus aureus ST398 in pig farming; evidence from a surveillance study in southern Italy. Antimicrob. Resist. Infect. Control 8:187. https://doi.org/10.1186/ s13756-019-0650-z.

Poutrel, B., S. Bareille, G. Lequeux, and F. Leboeuf. 2018. Prevalence of mastitis pathogens in France: Antimicrobial susceptibility of Staphylococcus aureus, Streptococcus uberisand Escherichia coli. J. Vet. Sci. Technol. 9:522. https://doi.org/10.4172/2157-7579 .1000522 .

Prashanth, K., K. R. Rao, P. Vivek Reddy, R. Saranathan, and A. R. Makki. 2011. Genotypic characterization of Staphylococcus aureus obtained from humans and bovine mastitis samples in India. J. Glob. Infect. Dis. 3:115-122. https://doi.org/10.4103/0974-777X .81686 .

Pumipuntu, N., W. Tunyong, N. Chantratita, P. Diraphat, P. Pumirat, N. Sookrung, W. Chaicumpa, and N. Indrawattana. 2019. Staphylococcus spp. associated with subclinical bovine mastitis in central and northeast provinces of Thailand. PeerJ 7:e6587. https://doi .org/10.7717/peerj.6587.

Sabat, A., J. Krzyszton-Russjan, W. Strzalka, R. Filipek, K. Kosowska, W. Hryniewicz, J. Travis, and J. Potempa. 2003. New method for typing Staphylococcus aureus strains: Multiple-locus variablenumber tandem repeat analysis of polymorphism and genetic relationships of clinical isolates. J. Clin. Microbiol. 41:1801-1804. https://doi.org/10.1128/JCM.41.4.1801-1804.2003.

Sakwinska, O., M. Giddey, M. Moreillon, D. Morisset, A. Waldvogel, and P. Moreillon. 2011. Staphylococcus aureus host range and human-bovine host shift. Appl. Environ. Microbiol. 77:5908-5915. https://doi.org/10.1128/AEM.00238-11.

Sato, T., M. Usui, N. Konishi, A. Kai, H. Matsui, H. Hanaki, and Y. Tamura. 2017. Closely related methicillin-resistant Staphylococcus aureus isolates from retail meat, cows with mastitis, and humans in Japan. PLoS One 12:e0187319. https://doi.org/10.1371/journal .pone.0187319.

Schmidt, T., M. M. Kock, and M. M. Ehlers. 2017. Molecular characterization of Staphylococcus aureus isolated from bovine mastitis 
and close human contacts in South African dairy herds: Genetic diversity and inter-species host transmission. Front. Microbiol. 8:511. https://doi.org/10.3389/fmicb.2017.00511.

Schnitt, A., and B.-A. Tenhagen. 2019. Risk factors for the occurrence of methicillin-resistant Staphylococcus aureus in dairy herds: An update. Foodborne Pathog. Dis. https://doi.org/10.1089/fpd.2019 .2638 (published online ahead of print, 2019 Aug 28).

Sharma, M., J. Nunez-Garcia, A. M. Kearns, M. Doumith, P. R. Butaye, M. A. Argudín, A. Lahuerta-Marin, B. Pichon, M. AbuOun, J. Rogers, R. J. Ellis, C. Teale, and M. F. Anjum. 2016. Livestockassociated methicillin resistant Staphylococcus aureus (LA-MRSA) clonal complex (CC) 398 isolated from UK animals belong to European lineages. 2016. Front. Microbiol. 7:1741.

Stefani, S., D. R. Chung, J. A. Lindsay, A. W. Friedrich, A. M. Kearns, H. Westh, and F. M. Mackenzie. 2012. Meticillin-resistant Staphylococcus aureus (MRSA): Global epidemiology and harmonisation of typing methods. Int. J. Antimicrob. Agents 39:273-282. https:/ /doi.org/10.1016/j.ijantimicag.2011.09.030.

Sztachańska, M., W. Barański, T. Janowski, J. Pogorzelska, and S. Zduńczyk. 2016. Prevalence and etiological agents of subclinical mastitis at the end of lactation in nine dairy herds in North-East Poland. Pol. J. Vet. Sci. 19:119-124. https://doi.org/10.1515/pjvs $-2016-0015$.

Tavakol, M., R. G. Riekerink, O. C. Sampimon, W. J. van Wamel, A. van Belkum, and T. J. Lam. 2012. Bovine-associated MRSA ST398 in the Netherlands. Acta Vet. Scand. 54:28. https://doi .org/10.1186/1751-0147-54-28.

Tegegne, H. A., M. Florianová, T. Gelbíčová, R. Karpíšková, and I. Koláčková. 2019. Detection and molecular characterization of methicillin-resistant Staphylococcus aureus isolated from bulk tank milk of cows, sheep, and goats. Foodborne Pathog. Dis. 16:68-73. https://doi.org/10.1089/fpd.2018.2511.

Tenhagen, B. A., B. Vossenkuhl, A. Käsbohrer, K. Alt, B. Kraushaar, B. Guerra, A. Schroeter, and A. Fetsch. 2014. Methicillin-resistant Staphylococcus aureus in cattle food chains - Prevalence, diversity, and antimicrobial resistance in Germany. J. Anim. Sci. 92:27412751. https://doi.org/10.2527/jas.2014-7665.

Tenover, F. C., E. A. Gay, S. Frye, S. J. Eells, M. Healy, and J. E. McGowan Jr.. 2009. Comparison of typing results obtained for methicillin-resistant Staphylococcus aureus isolates with the DiversiLab system and pulsed-field gel electrophoresis. J. Clin. Microbiol. 47:2452-2457. https://doi.org/10.1128/JCM.00476-09.

Turner, N. A., B. K. Sharma-Kuinkel, S. A. Maskarinec, E. M. Eichenberger, P. P. Shah, M. Carugati, T. L. Holland, and V. G. Fowler Jr.. 2019. Methicillin-resistant Staphylococcus aureus: An overview of basic and clinical research. Nat. Rev. Microbiol. 17:203-218. https://doi.org/10.1038/s41579-018-0147-4.

Udo, E. E. 2013. Community-acquired methicillin-resistant Staphylococcus aureus: The new face of an old foe? Med. Princ. Pract. 22(s1):20-29. https://doi.org/10.1159/000354201.

van Duijkeren, E., P. Hengeveld, T. P. Zomer, F. Landman, T. Bosch, A. Haenen, and A. van de Giessen. 2016. Transmission of MRSA between humans and animals on duck and turkey farms. J. Antimicrob. Chemother. 71:58-62. https://doi.org/10.1093/jac/dkv313.

van Duijkeren, E., M. Moleman, M. M. Sloet van OldruitenborghOosterbaan, J. Multem, A. Troelstra, A. C. Fluit, W. J. B. van Wamel, D. J. Houwers, A. J. de Neeling, and J. A. Wagenaar. 2010. Methicillin-resistant Staphylococcus aureus in horses and horse personnel: an investigation of several outbreaks. Vet. Microbiol. 141:96-102. https://doi.org/10.1016/j.vetmic.2009.08.009.

van Duijkeren, E., M. J. Wolfhagen, A. T. Box, M. E. Heck, W. J. Wannet, and A. C. Fluit. 2004. Human-to-dog transmission of methicillin-resistant Staphylococcus aureus. Emerg. Infect. Dis. 10:2235-2237. https://doi.org/10.3201/eid1012.040387.

Vanderhaeghen, W., T. Cerpentier, C. Adriaensen, J. Vicca, K. Hermans, and P. Butaye. 2010. Methicillin-resistant Staphylococcus aureus (MRSA) ST398 associated with clinical and subclinical mastitis in Belgian cows. Vet. Microbiol. 144:166-171. https://doi .org/10.1016/j.vetmic.2009.12.044.

Verkade, E., M. Kluytmans-van den Bergh, B. van Benthem, B. van Cleef, M. van Rijen, T. Bosch, L. Schouls, and J. Kluytmans. 2014. Transmission of methicillin-resistant Staphylococcus aureus CC398 from livestock veterinarians to their household members. PLoS One 9:e100823. https://doi.org/10.1371/journal.pone.0100823.

Votintseva, A. A., R. R. Miller, R. Fung, K. Knox, H. Godwin, T. E. A. Peto, D. W. Crook, R. Bowden, and A. S. Walker. 2014. Multiple-strain colonization in nasal carriers of Staphylococcus aureus. J. Clin. Microbiol. 52:1192-1200. https://doi.org/10.1128/ JCM.03254-13.

Zhou, W., X. Li, T. Osmundson, L. Shi, J. Ren, and H. Yan. 2018. WGS analysis of ST9-MRSA-XII isolates from live pigs in China provides insights into transmission among porcine, human and bovine hosts. J. Antimicrob. Chemother. 73:2652-2661. https://doi .org/10.1093/jac/dky245.

\section{ORCIDS}

Tomasz Jagielski @ https://orcid.org/0000-0001-9553-5742 